\title{
THE ASSOCIATIONS BETWEEN SOCIOECONOMIC STATUS AND
}

\section{LIFESTYLE FACTORS IN EUROPEAN ADOLESCENTS: A POPULATION-}

\section{BASED STUDY}

\author{
Dario Novak ${ }^{1}$, Štefan Lovro ${ }^{1}$, Branislav Antala ${ }^{2}$, Arunas Emeljanovas ${ }^{3}$, Brigita Mieziene ${ }^{3}$, \\ Ivana Milanovićc ${ }^{4}$ Snežana Radisavljević-Janićc \\ ${ }^{1}$ Faculty of Kinesiology, University of Zagreb, 10000 Zagreb, Croatia \\ ${ }^{2}$ Faculty of Physical Education and Sports, Comenius University, Bratislava, Slovakia \\ ${ }^{3}$ Sports Education Faculty, Lithuanian Sports University, Kaunas, Lithuania \\ ${ }^{4}$ Faculty of Sport and Physical Education, Belgrade, Serbia
}

\begin{abstract}
The main purpose of the present study was to determine the associations between socioeconomic status (SES) and lifestyle factors. In this cross-sectional study, participants were 3,072 adolescents from two European countries of Lithuania and Serbia. The dependent variable was SES, while independent variables were gender, adherence to a Mediterranean diet, body-mass index, self-rated health, psychological distress, moderateto-vigorous physical activity and sedentary behaviour. The associations between dependent and independent variables were analysed by using logistic regression analysis. In univariate model, middle/high SES was associated with higher adherence to a Mediterranean diet ( $\left.\mathrm{p}_{\text {trend }}=0.003\right)$, good self-rated health (OR 1.51; $95 \%$ CI 1.12 to 2.05) and meeting recommendations of moderate-to-vigorous physical activity (OR 2.09; $95 \%$ CI 1.45 to 3.00 ), yet inversely associated with psychological distress (OR $0.81 ; 95 \%$ CI 0.66 to 0.99 ) and sedentary behaviour (OR 0.80; 95 \% CI 0.68 to 0.94). No associations were found between SES and body-mass index and gender. In multivariate model, the same associations occurred between middle/high SES and lifestyle factors. In conclusion, special strategies and policies, based on more affordable nutrition and participation in moderate-tovigorous physical activity, should be implemented within the system.
\end{abstract}

Key words: material status, physical activity, nutrition, adolescents, logistic regression

DOI 10.1515/afepuc-2017-0011

(C) Acta Facultatis Educationis Physicae Universitatis Comenianae 


\section{Introduction}

Socioeconomic status (SES) has been consistently associated with several lifestyle factors, especially in adult population [1 - 3]. For instance, a few studies have reported, that adults with higher monthly income were more likely to be overweight/obese [1,4]. Moreover, one recent study showed that relatively high educational attainment was associated with lower risk of mortality and cardiovascular diseases [2]. Also, low income was associated with mental disorders in general population [5].

In adolescents, previous studies have shown that SES was associated with diet quality, i.e. consuming high-energy but low-nutrient dense products [6 - 8]. Specifically, one study showed that adolescents, who came from low-income families, but from developed countries, were more likely to become obese, due to their low-nutrient diet and lower levels of physical activity [9]. Moreover, dietary habits that children and youth established in childhood were often associated with the same habits they maintain in adulthood [10]. In relation with nutrition, findings showed that SES had strong impact on physical activity in adolescents $[11,12]$. One study reported, that maternal education level positively influenced on self-reported physical activity in adolescents [13]. Moreover, another study showed that income status and maternal education were both positively associated with higher levels of physical activity assessed with accelerometer [14]. Self-rated health represents one of the most commonly used health indicator, composed of social, psychological and biological determinants [15]. One of these determinants is SES, which has been described as a risk factor for poor self-rated health in adolescents [16 - 18]. Another determinant, which has been investigated in adolescents, is psychological distress. One recent systematic review showed inverse association between SES and psychological distress in both children and adolescents [19]. Moreover, the same study showed that low family income and poor parental education were strong predictors for mental health problems [19]. Along with the abovementioned lifestyle factors, sedentary behaviour, along with the childhood adiposity, has often been associated with poor SES, especially in children and adolescents [20 - 22].

To authors knowledge and after an extensive literature research, there has been lacking of studies investigating separate and simultaneous associations between potential lifestyle factors with SES, especially in European adolescents from developing countries. Thus, the main purpose of the present study was to investigate the associations between SES and lifestyle behaviours in adolescents. We hypothesised, that SES would be positively associated with self-rated health, moderate-tovigorous physical activity and adherence to a Mediterranean diet, yet inversely associated with bodymass index, psychological distress and sedentary behaviour and with no significant associations with gender. 


\section{Materials and Methods}

\section{Participants and testing protocol}

In this cross-sectional study, participants were 3,200 adolescents from two European countries: Lithuania and Serbia. A random sampling approach was used to select high school. From total, 15 schools from Lithuania and 10 schools from Serbia were selected. Of these, 3,072 students ( $61.7 \%$ of female students; mean age $17.06 \pm 1.34$ years; mean height $174.53 \pm 9.60 \mathrm{~cm}$; mean weight $65.60 \pm 13.08 \mathrm{~kg}$; mean BMI $\left.21.38 \pm 3.14 \mathrm{~kg} / \mathrm{m}^{2}\right)$ responded to the study $(96.0 \%)$, which is similar to some other studies [23]. Before the study began, all participants and their parents/guardians had given informed consent to participate in the study. The Ethics Committee of the Faculty of Kinesiology approved all the procedures performed in this study.

Data were collected between January and March in the 2015/2016 school year performed by 3-trained doctors. They also took care, that the procedure was the same for all participants. Participants completed the questionnaires during class hours in presence of researchers. At the beginning of the class, researches explained the main purpose of the study and study protocol. After the explanation, students completed the questionnaires and put them inside the box. The researchers were always available to explain or clarify the questions. The whole procedure took about 30 minutes and was anonymous.

\section{Dependent variable}

To assess self-perceived SES, we used data from both parents' occupation at the time the study was conducted. SES was categorized into three categories: (1) high SES (occupations like managers or professionals), (2) middle SES (white collar) and (3) low SES (blue collar). We binarised the outcome, where middle and high SES collapsed in „middle/high“ SES (responses from the questionnaire in the range 2 - 4) and „low“ SES (responses from the questionnaire in the range 5 - 6) [24].

\section{Lifestyle factors}

To assess adherence to a Mediterranean diet, KIDMED questionnaire was used. It is comprised of 16 questions; 12 of them denote high adherence to a Mediterranean diet, while 4 of them denote low adherence to a Mediterranean diet. Those 12 questions are scored with +1 and those 4 with -1 . The responses are summed up, where higher result denote higher adherence to a MD. Score $\leq 3$ represents low adherence, $4-7$ average adherence and $\geq 8$ good adherences to a Mediterranean $\operatorname{diet}[25]$.

We used International Physical Activity Questionnaire-short form (IPAQ-short) to assess different levels of physical activity in the last 7 days. The results are expressed as metabolic equivalents in MET-min/week [26]. For the purpose of this study, we binarised the outcome, where 
participants who participated in $<60 \mathrm{~min} /$ day or $420 \mathrm{~min} /$ week were categorized as insufficiently active, while those $\geq 60 \mathrm{~min} /$ day or $\geq 420 \mathrm{~min} /$ week sufficiently active [27]. Previous studies have shown that IPAQ have adequate reliability and validity [26].

To determine general health, one-item question was used: „In general, how would you perceive your health? “. Responses were arranged across the five-item Likert scale: (1) very poor, (2) poor, (3) fair, (4) good and (5) excellent [28]. We binarised the outcome, where responses ,,very poor“ and ,poor“ collapsed into category ,poor health“, while responses „fair“, „,good“ and „,excellent“ into „good health“. Previous studies have shown that self-rated health served as a good and reliable predictor of mortality in adolescents [29, 30].

We considered psychological distress, as another factor, which might be associated with SES. To assess psychological distress, we used a six-item Kessler scale: „How often did you feel nervous during the past month?“, „How often did you feel hopeless during the last month?“, „How often did you feel restless or fidgety during the last month?“, „How often did you feel so depressed that nothing could cheer you up during the last month?“, „How often did you feel that everything was and effort during the last month?“ and „How often did you feel worthless during the last month?“. Each question is scored in the range $0-4$ (none of the time-all of the time). Scores from all six questions were summed up (result in the range 0 - 24). Lower result indicates lower level of psychological distress, while higher result indicates higher level of psychological distress. We binarised the results, where scores between 0 - 12 represented participants without psychological distress and scores $\geq 13$ represented participants with psychological distress [31].

As additional potential factor, we used body-mass index from self-reported height and weight of the participants. We binarised the outcome, where participants $<25 \mathrm{~kg} / \mathrm{m}^{2}$ were categorized as normal, while those $\geq 25 \mathrm{~kg} / \mathrm{m}^{2}$ were categorized as overweight/obese.

Sedentary behaviour was assessed by single-item question: „In the last 7 days, how much time did you spend sitting on a week day? “. The responses were expressed as minutes per day. Responses were binarised as $\leq 120 \mathrm{~min} /$ day or $>120 \mathrm{~min} /$ day [32].

\section{Data analysis}

For categorical variables, we used frequencies and percentages. Differences between „low“ vs. ,middle/high“ SES participants in categorical variables were analyzed by using Chi-square test. Next, the associations between middle/high SES and lifestyle factors were analyzed by using logistic regression analysis with odds ratios (ORs) and $95 \%$ confidence interval (95\% CI). In the univariate model, we calculated the associations between middle/high SES and each lifestyle factor entered separately into the model ( 7 models). In the second analysis, we calculated the associations between middle/high SES and lifestyle factors entered simultaneously into the model (1 model). We also calculated $\beta$ coefficients with $95 \%$ CI by using bootstrapping set on 1,000 samples. All the statistical 
procedures made in this study were analyzed by using SPSS ver. 22 (Statistical Package for Social Sciences, Chicago, Il: USA). Statistical significance was set up at $\mathrm{p} \leq 0.05$ and were two-sided tests.

\section{Results}

Basic descriptive statistics of the study participants are presented in Table 1. Higher adherence to a Mediterranean diet was shown in participants who reported ,middle/high“ SES. Also, higher percentage of participants in ,middle/high“SES reported better general health $(\mathrm{p}=0.009)$. Interestingly, more participants in ,middle/high“ SES reported having high psychological distress, but this was not statistically significant. Moreover, higher percentage of participants in higher SES group met the recommendations for doing moderate-to-vigorous physical activity, according to the World Health Organization recommendations [27] and lower percentage $(69.4 \%$ vs. $74.0 \%)$ of them reported sedentary behaviour.

\section{Table 1}

Characteristics of the study participants

\begin{tabular}{|c|c|c|c|c|}
\hline Study variables & $\begin{array}{c}\text { Total } \\
(\mathbf{N = 3 , 0 7 2})\end{array}$ & $\begin{array}{c}\text { Low SES } \\
(\mathbf{N}=\mathbf{1 , 1 7 6})\end{array}$ & $\begin{array}{c}\text { Middle/high SES } \\
(\mathbf{N}=\mathbf{1 , 8 9 6})\end{array}$ & p value* $^{*}$ \\
\hline & $\mathrm{N}(\%)$ & $\mathrm{N}(\%)$ & $\mathrm{N}(\%)$ & \\
\hline Gender & & & & \\
\hline Male students & $1,449(47.2)$ & $543(46.2)$ & $906(47.8)$ & \\
\hline Female students & $1,623(52.8)$ & $633(53.8)$ & $990(52.2)$ & 0.393 \\
\hline KIDMED score & & & & \\
\hline Low adherence $(\leq 3)$ & $1,205(39.2)$ & $505(42.9)$ & $700(36.9)$ & \\
\hline Average adherence $(4-7)$ & $1,461(47.6)$ & $532(45.2)$ & $929(49.0)$ & \\
\hline Good adherence $(\geq 8)$ & $406(13.2)$ & $139(11.8)$ & $267(14.1)$ & 0.003 \\
\hline Body-mass index & & & & \\
\hline Normal $\left(<25 \mathrm{~kg} / \mathrm{m}^{2}\right)$ & $2,729(88.8)$ & $1,038(88.3)$ & $1,691(89.2)$ & \\
\hline Overweight/obesity $\left(\geq 25 \mathrm{~kg} / \mathrm{m}^{2}\right)$ & $343(11.2)$ & $138(11.7)$ & $205(10.8)$ & 0.444 \\
\hline Self-rated health & & & & \\
\hline Poor & $180(5.9)$ & $86(7.3)$ & $94(5.0)$ & \\
\hline Good & $2,892(94.1)$ & $1,090(92.7)$ & $1,802(95.5)$ & 0.009 \\
\hline Psychological distress & & & & \\
\hline Low & $2,600(84.6)$ & $1,014(86.2)$ & $1,586(83.6)$ & \\
\hline High & $472(15.4)$ & $162(13.8)$ & $310(16.4)$ & 0.057 \\
\hline $\begin{array}{c}\text { Moderate-to-vigorous } \\
\text { physical activity }\end{array}$ & & & & \\
\hline$<60$ min/day (<420 min/week) & $2,902(94.5)$ & $1,136(96.6)$ & $1,766(93.1)$ & \\
\hline$\geq 60$ min/day $(\geq 420$ min/week) & $170(5.5)$ & $40(3.4)$ & $130(6.9)$ & $<0.001$ \\
\hline Sedentary behaviour & & & & \\
\hline$\leq 120$ min/day & $886(28.8)$ & $306(26.0)$ & $580(30.6)$ & \\
\hline$>120$ min/day & $2,186(71.2)$ & $870(74.0)$ & $1,316(69.4)$ & 0.007 \\
\hline$*$ Chi-square test & & & & \\
\hline
\end{tabular}

The associations between middle/high SES and lifestyle factors are presented in Table 2. In the univariate model, middle/high SES was associated with higher adherence to a Medierranean diet ( $\left.\mathrm{p}_{\text {trend }}=0.003\right)$, good self-rated health (OR 1.51; $95 \%$ CI 1.12 to 2.05 ) and participating in $\geq 60 \mathrm{~min} /$ day 
of moderate-to-vigorous physical activity (OR 2.09; $95 \%$ CI 1.45 to 3.00). Moreover, middle/high SES was inversely associated with psychological distress (OR 0.81; $95 \%$ CI 0.66 to 0.99 ) and sedentary behaviour (OR $0.80 ; 95 \%$ CI 0.68 to 0.94 ). When all the lifestyle factors were entered simultaneously into the model, middle/high SES remained associated with higher adherence to a Mediterranean diet ( $p_{\text {trend }}=0.008$ ), good self-rated health (OR 1.62; $95 \%$ CI 1.19 to 2.20) and participating in $\geq 60 \mathrm{~min} /$ day of moderate-to-vigorous physical activity (OR 2.07; $95 \% \mathrm{CI} 1.44$ to 2.98), yet inversely associated with psychological distress (OR 0.77; $95 \%$ CI 0.62 to 0.95 ) and sedentary behaviour (OR $0.80 ; 95 \%$ CI 0.67 to 0.94 ).

Table 2

ORs for middle/high SES

\begin{tabular}{|c|c|c|c|c|}
\hline \multirow{2}{*}{ Study variables } & \multirow{2}{*}{\begin{tabular}{|c|} 
Univariate results* \\
OR $(95 \% \mathrm{CI})$ \\
\end{tabular}} & \multirow{2}{*}{ p value } & \multirow{2}{*}{\begin{tabular}{|c|} 
Multivariate results** \\
OR $(95 \% \mathrm{CI})$ \\
\end{tabular}} & \multirow{2}{*}{ p value } \\
\hline & & & & \\
\hline \multicolumn{5}{|l|}{ Gender } \\
\hline Male students & Ref. & & Ref. & \\
\hline Female students & $0.94(0.81$ to 1.08$)$ & 0.385 & $0.95(0.82$ to 1.11$)$ & 0.545 \\
\hline \multicolumn{5}{|l|}{ KIDMED score } \\
\hline Low adherence $(\leq 3)$ & Ref. & & Ref. & \\
\hline Average adherence $(4-7)$ & $1.26(1.08$ to 1.47$)$ & 0.004 & $1.24(1.06$ to 1.45$)$ & 0.008 \\
\hline Good adherence $(\geq 8)$ & $1.39(1.10$ to 1.75$)$ & 0.006 & $1.35(1.07$ to 1.71$)$ & 0.012 \\
\hline$p$ trend & \multicolumn{2}{|l|}{0.003} & \multicolumn{2}{|l|}{0.008} \\
\hline \multicolumn{5}{|l|}{ Body-mass index } \\
\hline Normal $\left(<25 \mathrm{~kg} / \mathrm{m}^{2}\right)$ & Ref. & & Ref. & \\
\hline Overweight/obesity $\left(\geq 25 \mathrm{~kg} / \mathrm{m}^{2}\right)$ & $0.91(0.72$ to 1.15$)$ & 0.430 & $0.93(0.73$ to 1.17$)$ & 0.535 \\
\hline \multicolumn{5}{|l|}{ Self-rated health } \\
\hline Poor & Ref. & & Ref. & \\
\hline Good & $1.51(1.12$ to 2.05$)$ & 0.007 & $1.62(1.19$ to 2.20$)$ & 0.002 \\
\hline \multicolumn{5}{|l|}{ Psychological distress } \\
\hline Low & Ref. & & Ref. & \\
\hline High & $0.81(0.66$ to 0.99$)$ & 0.041 & $0.77(0.62$ to 0.95$)$ & 0.015 \\
\hline \multicolumn{5}{|l|}{$\begin{array}{l}\text { Moderate-to-vigorous } \\
\text { physical activity }\end{array}$} \\
\hline$<60 \mathrm{~min} /$ day $(<420 \mathrm{~min} /$ week $)$ & Ref. & & Ref. & \\
\hline$\geq 60 \mathrm{~min} /$ day $(\geq 420 \mathrm{~min} /$ week $)$ & $2.09(1.45$ to 3.00$)$ & $<0.001$ & 2.07 (1.44 to 2.98$)$ & $<0.001$ \\
\hline \multicolumn{5}{|l|}{ Sedentary behaviour } \\
\hline$\leq 120 \mathrm{~min} /$ day & Ref. & & Ref. & \\
\hline$>120 \mathrm{~min} /$ day & $0.80(0.68$ to 0.94$)$ & 0.007 & $0.80(0.67$ to 0.94$)$ & 0.006 \\
\hline
\end{tabular}

*examine the associations between SES and its factors entered separately into the model (7 models);

** examine the associations between SES and its factors entered simultaneously into the model (1 model) $\mathrm{p} \leq 0.05$

Coefficients between middle/high SES and lifestyle habits are presented in Table 3. Middle/high SES was positively associated with higher adherence to a Mediterranean diet, good selfrated health ( $\beta 0.41 ; 95 \% \mathrm{CI} 0.12$ to 0.74$)$ and participating in $\geq 60 \mathrm{~min} /$ day of moderate-to-vigorous physical activity ( $\beta 0.74 ; 95 \%$ CI 0.39 to 1.12 ), yet inversely associated with psychological distress ( $\beta-0.21 ; 95 \%$ CI -0.43 to -0.01$)$ and time spent in sedentary behaviour $(\beta-0.23 ; 95 \%$ CI -0.38 to 0.07). When all the variables were entered simultaneously into the multivariate model, middle/high SES remained associated with higher adherence to a Mediterranean diet, good self-rated health $(\beta$ 
$0.4895 \% \mathrm{CI} 0.16$ to 0.81 ) and participating in $\geq 60 \mathrm{~min} /$ day of moderate-to-vigorous physical activity ( $\beta 0.73 ; 95 \%$ CI 0.38 to 1.12$)$, yet inversely associated with psychological distress ( $\beta-0.26$; $95 \%$ CI 0.47 to -0.05$)$ and time spent in sedentary behaviour $(\beta-0.23 ; 95 \% \mathrm{CI}-0.40$ to -0.06$)$.

Table 3

Coefficients for middle/high SES

\begin{tabular}{|c|c|c|c|c|}
\hline \multirow{2}{*}{ Study variables } & \multirow{2}{*}{$\begin{array}{c}\text { Univariate results* } \\
\beta(95 \% \mathrm{CI}) \\
\end{array}$} & \multirow{2}{*}{ p value } & \multirow{2}{*}{\begin{tabular}{|c|} 
Multivariate results** \\
$\beta(95 \% \mathrm{CI})$ \\
\end{tabular}} & \multirow{2}{*}{ p value } \\
\hline & & & & \\
\hline \multicolumn{5}{|l|}{ Gender } \\
\hline Male students & Ref. & & Ref. & \\
\hline Female students & $-0.06(-0.21$ to 0.08$)$ & 0.394 & $-0.05(-0.20$ to 0.10$)$ & 0.537 \\
\hline \multicolumn{5}{|l|}{ KIDMED score } \\
\hline Low adherence $(\leq 3)$ & Ref. & & Ref. & \\
\hline Average adherence $(4-7)$ & $0.23(0.08$ to 0.39$)$ & 0.003 & $0.21(0.06$ to 0.38$)$ & 0.013 \\
\hline Good adherence $(\geq 8)$ & $0.33(0.09$ to 0.55$)$ & 0.005 & $0.30(0.07$ to 0.55$)$ & 0.010 \\
\hline \multicolumn{5}{|l|}{ Body-mass index } \\
\hline Normal $\left(<25 \mathrm{~kg} / \mathrm{m}^{2}\right)$ & Ref. & & Ref. & \\
\hline Overweight/obesity $\left(\geq 25 \mathrm{~kg} / \mathrm{m}^{2}\right)$ & $-0.09(-0.32$ to 0.16$)$ & 0.449 & $-0.07(-0.32$ to 0.18$)$ & 0.525 \\
\hline \multicolumn{5}{|l|}{ Self-rated health } \\
\hline Poor & Ref. & & Ref. & \\
\hline Good & $0.41(0.12$ to 0.74$)$ & 0.010 & $0.48(0.16$ to 0.81$)$ & 0.004 \\
\hline \multicolumn{5}{|l|}{ Psychological distress } \\
\hline Low & Ref. & & Ref. & \\
\hline High & $-0.21(-0.43$ to -0.01$)$ & 0.042 & $-0.26(-0.47$ to -0.05$)$ & 0.018 \\
\hline \multicolumn{5}{|l|}{$\begin{array}{l}\text { Moderate-to-vigorous } \\
\text { physical activity }\end{array}$} \\
\hline$<60 \mathrm{~min} /$ day $(<420 \mathrm{~min} /$ week $)$ & Ref. & & Ref. & \\
\hline$\geq 60 \mathrm{~min} /$ day $(\geq 420 \mathrm{~min} /$ week $)$ & $0.74(0.39$ to 1.12$)$ & $<0.001$ & $0.73(0.38$ to 1.12$)$ & 0.002 \\
\hline \multicolumn{5}{|l|}{ Sedentary behaviour } \\
\hline$\leq 120 \mathrm{~min} /$ day & Ref. & & Ref. & \\
\hline$>120 \mathrm{~min} /$ day & $-0.23(-0.38$ to -0.07$)$ & 0.008 & $-0.23(-0.40$ to -0.06$)$ & 0.009 \\
\hline
\end{tabular}

*examine the associations between SES and its factors entered separately into the model (7 models);

$* *$ examine the associations between SES and its factors entered simultaneously into the model (1 model). $\mathrm{P} \leq 0.05$

\section{Discussion}

The main purpose of the present study was to determine the associations between SES and lifestyle factors in adolescents from two European countries of Lithuania and Serbia.

Results from our study showed, that middle/high SES was positively associated with higher adherence to a Mediterranean diet, which is consistent to some other studies [33 - 35]. Studies showed, that children from low-income families were more vulnerable to have poor diet and to becoming obese [9]. Moreover, a poor quality diet has been associated with the affordability of good nutritional-dense food, since one study showed, that Mediterranean-type diet (i.e. fruits, vegetables, olive, fish) was much more expensive than ,western“ type diet [36], which is primary consisted of high-calorie, processed foods with longer durational life [37]. 
Our results also showed that adolescents who were moderate-to-vigorous physically active $\geq 60 \mathrm{~min} /$ day were more likely to have middle/high SES. One previous study showed positive associations between SES indicators (mother's education level and type of school) and physical activity (which was defined as participating in moderate-to-vigorous physical activity $>300$ $\mathrm{min} /$ week) [13]. Another study conducted on Nigerian adolescents reported, that leisure-time physical activity, active transportation, moderate-intensity activity and total physical activity were associated with higher SES [38]. Moreover, one study also showed the same results, where participants who participated in at least $60 \mathrm{~min} /$ day of moderate-to-vigorous physical activity, were categorized in the highest socioeconomic class. The study stated, that from the 32 countries included in the study, only one country showed no association between socioeconomic status and higher participation in moderate-to-vigorous physical activity [39].

Our findings showed positive associations between SES and self-rated health. One recent study showed, that despite the differences between countries, higher socioeconomic status (family income, occupation status) was associated with a good general health state [40]. However, the same study showed that self-rated health was not often associated with higher occupational position in Southern and Eastern European countries, probably because of salaries are not high enough than in Western or Northern countries [40]. One possible reason for such association is that, in general, the effect of education is decreasing in Europe, pointing out that school system and being educated represent the effect of social expenditure in both public and private education [41]. In general, a few studies showed positive associations between SES and self-rated health in adolescents $[16,17$, and 42]. According to some studies, the most important SES factors influencing self-rated health are family conflicts [43], unkind and unhelpful school colleagues [16], physical health status [17] low income and lacking of educational resources [44].

Results from our study showed strong inverse association between SES and psychological distress, which is consistent to some previous studies [19, 45, and 46]. Specifically, it has been reported, that low family SES can influence on adolescent mental health, especially through inadequate nutrition (low-nutrient diet), family dysfunction, poor parenting and parental mental problems [47]. Interestingly, ones study found the U-shaped association between SES and psychological distress, i.e. adolescents from both low- and high- income families experience psychological distress [46]. This could be explained by the fact, that high-income parents have higher expectations for their children's educational attainment and that often lead to stress experience in children [48]. Also, according to Reiss [19], theoretical approaches and social class classification often cause a cycle of deprivation and mental health problems, pointing out that the adolescents are the risk group for such conditions. 
Our findings showed the inverse association between SES and sedentary behaviour in adolescents, which is similar to some other studies [12, 34, and 49]. Specifically, parental education and professional level were both associated with sedentary behaviour, where regular physical activity levels in parents were often transferred to their children. Also, results from Bibiloni et al. [34] showed, that the access to outdoor and indoor sport facilities were strongly associated with the parental educational and profession level, due to their higher financial status and affordance of such activities.

Our study has several limitations. First, due to the cross-sectional design, we cannot exclude possible reverse associations, that is, middle/high SES is associated with included lifestyle factors in our study. Second, we used subjective measures to assess dependent and independent variables. Specifically, although assessed questionnaires in this study have previously showed good metric properties, we cannot exclude the possibility of over- or under- estimation of certain parameters. For example, the subjective method for assessing physical activity often leads to overestimation and great variability with the objective measures [50]. Also, we used self-reported measure for height and weight. Previous studies have showed, that both male and, especially female adolescents, tended to underestimate their body-mass index [51], which might potentially lead to no association between body-mass index and SES in our study. Moreover, the recall of sedentary behaviour could also possibly lead to bias [52].

\section{Conclusions}

In conclusion, results from our study showed positive associations between adherence to a Mediterranean diet, physical activity and self-rated health with SES, yet inverse associations between psychological distress and sedentary behaviour with SES. Our findings suggest that SES plays the important role in adolescent's lifestyle, where their parents can afford more quality diet and participating in organized leisure-time physical activity for them. Future longitudinal studies should be performed, in order to establish the true causalities between SES and lifestyle factors, especially in developing countries, where there are still great socioeconomic disparities between high- and lowincome families.

\section{Acknowledgements}

The authors would like to thank the students and teachers for their enthusiastic participation in the study. Article was prepared as a part of Dario Novak SAIA scholarship stay 2017. 


\section{References}

1. AFFUSO, O., J. STEVENS, D. CATELliER, R. G. MCMURRAY, D. S. WARD, L. LYTLE, M. S. SOTHERN \& D. R. YOUNG, 2011. Validity of self-reported leisure-time sedentary behavior in adolescents. J. Negat. Result Biomed. doi:10.1186/1477-5751-10-2.

2. AlVAREZ-GALVEZ, J., M. RODERO-COSANO, M. MOTRICO, J. A. SALINAZ-PEREZ, C. GARCIA-ALONSO \& L. SALVADOR-CARULLA, 2013. The impact of socio-economic status on self-rated health: study of 29 countries using European social surveys (2002-2008). Int. J. Environ. Res. Public Health. 10, 747-761.

3. BIBILONI, M. M., J. PICH, A. CÓRDOVA, A. PONS \& J. A. TUR, 2012. Associations between sedentary behaviour and socioeconomic factors, diet and lifestyle among the Balearic Island adolescents. BMC Public Health. doi: 10.1186/1471-2458-12-718.

4. BONACCIO, M. A. E. BONANNI, A. DI CASTELNUOVO, F. DE LUCIA, M.B. DONATI, G. DE GAETANO \& L. IACOVIELLO, 2012. Low income is associated with poor adherence to a Mediterranean diet and a higher prevalence of obesity: Cross-sectional results from the Moli-sani study. BMJ Open. doi:10.1136/bmjopen-2012-001685.

5. BORRACCINO, A., P. LEMMA, R. J. IANOTTI, A. ZAMBON, P. DALMASSO, G. LAZZERI, M. GIACCHI \& F. CAVALLO, 2009. Socioeconomic effects on meeting physical activity guidelines: comparisons of 32 countries. Med. Sci. Sports Exerc. 41, 749-756.

6. BREIDABLIK, H. J., E. MELAND \& S. LYDERSEN, 2008. Self-rated health in adolescence: a multifactorial composite. Scand. J. Public Health, 36, 12-20.

7. COSTARELLI, V. \& Y. MANIOS, 2009. The influence of socioeconomic status and ethnicity on childrens' excess of body weight. Nutr. Food Sci. 39, 676-684.

8. CRAiG, C. L., A. L. MARShall, M. SJÖStrÖM, A. E. BAUMAN, M. L. BOOTH, B. E. AINSWORTH, M. PRATT, U. EKELUND, A. YNGVE, J. F. SALliS \& P. OJA, 2003. International physical activity questionnaire: 12-country reliability and validity. Med. Sci. Sports Exerc. 35, 1381-1395.

9. DARMON, N. \& A. DREWNOWSKI, 2008. Does social class predict diet quality? Am. J. Clin. Nutr. 87, 1107-1117.

10. De REZENDE, L. F., C. M. AZEREDO, D. D. CANELLA, R. M. CLARO, I. R. De CASTRO, R. B. LEVY \& O. DO CARMO LUIZ, 2014. Socioedemographic and bihevioral factors associated with physical activity in Brazilian adolescents. BMC Public Health. doi:10.1186/14712458-14-485.

11. DRENOWSKI, A. \& N. DARMON, 2005. The economics of obesity: dietary energy density and energy cost. Am. J. Clin. Nutr. 82, 265-273. 
12. ERIKSSON, I., A. L. UNDÉN \& S. ELOFSSON, 2001. Self-rated health. Comparisons between three different measures. Results from a population study. Int. J. Epidemiol. 30, 326-333.

13. EUROSTAT , 2012. General Government Expenditure. Government Expenditure on Culture an Education. European commission, Available online:

http://epp.eurostat.ec.europa.eu/statistics_explained/index.php/General_government_expenditur e_statistics\#Government_expenditure_on_culture_and_education (accessed on 17 November 2016).

14. FERrEIRA, C. A., C. A. MOLENA, R. G. MARQUES, A.T. ARASAKI, F. FOSSATI \& M. CÍCERO, 2009. Prevalence of physical inactivity and associated factors among adolescents. Rev. Assoc. Med. Bras. 55, 523-528.

15. GILliSON, F. B., M. STANDAGE \& S. M. SKEVINGTON, 2006. Relationships among adolescents' weight perceptions, exercise goals, exercise motivation, quality of life and leisuretime exercise behaviour: A self-determination theory approach. Health Educ. Res. 21, 836-847.

16. HANSON, M. D. \& E. Chen, 2007.Socioeconomic status, race, and body-mass index : the mediating role of physical activity and sedentary behaviors during adolescence. J. Pediatr. Psychol. 32, 250-259.

17. JOHNSON, P. B. \& L. RICHTER, 2002. The relationship between smoking, drinking, and adolescents' self-perceived health and frequency of hospitalization: analyses from the 1997 National Household Survey on Drug Abuse. J. Adolesc. Health. 30,175-183.

18. KACHI, Y. \& E. ANDO, 2016. Socioeconomic disparities in psychological distress in a nationally representative sample of Japanese adolescents: A time trend study. Aust. NZ J. Psychiat. doi:10.1177/0004867416664142.

19. KARADEMAS, E. C., N. PEPPA, A. FOTIOU \& A. KOKKEVI, 2006. Family, school and health in children and adolescents: findings from the 2006 HBSC study in Greece. J. Health Psychol. 13, 1012-1030.

20. KARVONEN, S. \& O. RAHKONEN, 2011. Subjective social status and health in young people. Sociol. Health Illn. 33, 372-383.

21. KEIHAN RODRIGUES MATSUDO, V., G. L. DE MORAES FERRARI, T. L. ARAÚJO, L. C. OLIVEIRA, E. MIRE, T. V. BARREIRA, C. TUDOR-LOCKE \& P. KATZMARZYK, 2016. Socioeconomic status indicators, physical activity, and overweight/obesity in Brazilian children. Rev. Paul. Pediatr. 34, 162-170.

22. KESSLER, R. C., P. R. BARKER, L. J. COLPE, J. F. EPSTEIN, J. C. GFOERER, E. HIRIPI, M. J. HOWES, S. L. NORMAND, R. W. MANDERSCHEID, E. E. WALTERS \& A. M. ZASLAVSKY, 2003. Screening for serious mental ilness in the general population. Arch. Gen. Psychiatry. 60, 184-189. 
23. KOIVUSILTA, L., R. ARJA \& V. ANDRES, 2003. Health behavior and health in adolescence as predictors of educational level in adulthood: a follow-up study from Finland. Soc. Sci. Med. 57, 577-593.

24. KURTH, B. M. \& U. ELLERT, 2010. Estimated and measured BMI and self-perceived body image of adolescents in Germany. Part 1 - General implications for correcting prevalence estimations of overweight and obesity. Obes. Facts. 3, 181-190.

25. KWON, J. A. \& K. A. WICKRAMA, 2014. Linking family economic pressure and supportive parenting to adolescent health behaviors: two developmental pathways leading to health promoting and health risk behaviors. J. Youth Adolesc. 43, 1176-1190.

26. LA TORRE, G., D. MASALA, E. DE VITO, E. LANGIANO, G. CAPELLI \& W. RICCIARDI, 2006. Physical activity and socio-economic status collaborative group. Extra-curricular physical activity and socioeconomic status in Italian adolescents. BMC Public Health. 6, 22.

27. LARSON, J. S., 1996. The World Health Organization's definition of health: social versusu spiritual health. Soc. Indic. Res. 38, 181-192.

28. LOPEZ, C. N., M. A. MARTíNEZ-GONZÁLEZ, A. SÁNCHEZ-VILlEGAS, A. ALONSO, A. M. PIMENTA \& M. BES-RASTROLLO, 2009. Cost of Mediterranean and western dietary patterns in a Spanish cohort and their relationship with prospective weight change. J. Epidemiol. Community Health. 63, 920-927.

29. MATHIESON, A. \& T. KOLLER, 2006. Addressing the socioeconomic determinants of healthy eating habits and physical activity levels among adolescents. WHO/HBSC FORUM 2006. Copenhagen: World Health Organization.

30. McNAUGHTON, S. A., K. BALL, G. D. MiSHRA \& D. A. CRAWFORD, 2008. Dietary patterns of adolescents and risk of obesity and hypertension. J. Nutr. 138, 364-370.

31. MECHANIC, D. \& S. HANSELL, 1987. Adolescent competence, psychological well-being, and self-assessed physical health. J. Health Soc. Behav. 28, 364-374.

32. MEIRELES, A. L., C. COELHO XAVIER, F. A. PROIETTI \& W. T. CAIAFFA, 2015. Influence of individual and socio-environmental factors on self-rated health in adolescents. Rev. Bras. Epidemiol. 18, 538-551.

33. MENDOZA, A. J., A. DREWNOWSKI \& D. A. CHRISTAKIS, 2007. Dietary energy density is associated with obesity and the metabolic syndrome in US adults. Diabetes Care. 30, 974-979.

34. MOLARIUS, A., K. BERGLUND, C. ERIKSSON, H. G. ERIKSSON, M. LINDÉN-BOSTRÖM, E. NORDSTRÖM, C. PERSSON, L. SAHLQVIST, B. STARRIN \& B. YDREBORG, 2009. Mental health symptoms in relation to socio-economic conditions and lifestyle factors - a population-based study in Sweden. BMC Public Health. doi:10.1186/1471-2458-9-302. 
35. MOTA, J., F. FIDALGO, R. SILVA, R. C. RIBEIRO, R. SANTOS, J. CARVALHO \& M. P. SANTOS, 2008. Relationship between physical activity, obesity and meal frequency in adolescents. Ann. Hum. Biol. 35, 1-10.

36. NOVAK, D., E. SUZUKI \& I. KAWACHI, 2015. Are family, neighbourhood and school social capital associated with higher self-rated health among Croatian high-school students? A popualtion-based study. BMJ Open. doi:10.1136/bmjopen-2014-007184.

37. OGDEN, C. L., M. M. LAMB, M. D. CARROLL \& K. M. FLEGAL, 2010. Obesity and socioeconomic status in adolescents: United States, 2005-2008. NCHS Data Brief. 50, 1-8.

38. OYEYEMI, A. L., C. M. ISHAKU, J. OYEKOLA, H. D. WAKAWA, A. LAWAN, S. YAKUBU \& A. Y. OYEYEMI, 2016. Patterns and associated factors of physical activity among adolescents in Nigeria. PloS ONE . doi:10.1371/journal.pone.0150142.

39. PAGE, R. M. \& J. SUWANTEERANGKUL, 2009. Self-rated health, phycosocial functioning, and health-related behavior among Thai adolescents. Pediatr. Int. 51, 120-125.

40. RAMIĆ, E., S. DURAKOVIĆ, E. KARIĆ, O. MUJANOVIĆ \& E. ALIBAŠIĆ, 2009. Influence of lifestyle on overweight and obesity in school-age children. Med Arch. 63, 284-287.

41. REISS, F., 2013. Socioeconomic inequalities and mental health problems in children and adolescents. Soc. Sci. \& Med. 90, 24-31.

42. SERRA-MAJEM, L., L. RIBAS, J. NGO, R. M. ORTEGA, A. GARCIA \& C. PEREZRODRIGO, 2004. Food, youth and the Mediterranean diet in Spain. Development of KIDMED, Mediterranean Diet Quality Index in children and adolescents. Public Health Nutr. 7, 931-935.

43. SHREWSBURY, V. \& J. WARDLE, 2008. Socioeconomic status and adiposity in childhood: a systematic review of cross-sectional studies 1990-2005. Obesity. 16, 275-284.

44. STAMATAKIS, E., J. WARDLE \& T. J. COLE, 2010. Childhood obesity and overweight prevalence trends in England: evidence for growing socioeconomic disparities. Int. J. Obesity. 34, 41-47.

45. TREMBLAY, M. S., A. G. LEBLANC, I. JANSSEN, M. E. KHO, A. HICKS, K. MURUMETS, R. C. COLLEY \& M. DUGGAN, 2011. Canadian sedentary behaviour guidelines for children and youth. Appl. Physiol. Nutr. Metabl. 36, 59-64.

46. VINGILIS, E. R., T. J. WADE \& E. ADLAF, 1998. What factors predict student self-rated physical health? J. Adolesc. 21, 83-97.

47. WANG, Z., N. M. BYRNE, J. A. KENARDY \& A. P. HILLS, 2005. Influences of ethnicity and socioeconomic status on the body dissatisfaction and eating behavior of Australian children and adolescents. Eat. Behav. 6, 23-33.

48. WOODWARD, M., S. A. E. PETERS, G. D. BATTY, H. UESHIMA, J. WOO, G. G. GILES, F. BARZI, S. C. HO, R. R. HUXLEY, H. ARIMA, X. FANG, A. DOBSON \& T. LAM HING, 
2015. Socioeconomic status in relation to cardiovascular disease and cause-specific mortality: a comparison of Asian and Australasian populations in a pooled analysis. BMJ Open, 5, e006408.

49. WORLD HEALTH ORGANIZATION, 2014. Social determinants of mental health. WHO Press; Geneva, Switzerland, pp. 1-52.

50. WORLD HEALTH ORGANIZATION, 2011. WHO global strategy of on diet, physical activity and health. WHO Press, Geneva, Switzerland.

51. YAMAMOTO, Y. \& S. HOLLOWAY, 2010. Parental expectations and children's academic performance in sociocultural context. Educ. Psychol. Rev. 22, 189-214.

52. ZHANG, Q. \& Y. WANG, 2004. Trends in the assocition between obesity and socioeconomic status in U.S. adults: 1971-2000. Obesity, 12, 1622-1632. 